\title{
Conservative Treatment of Tuberculosis of the Spine in Patients with no Neurological Deficits

\section{ABSTRACT}

Background: Patients who have both neurological impairment and kyphotic deformity can be treated medically, and this treatment can be achieved with antituberculous drugs alone.

Objective: To evaluate conservative medical management of patients with tuberculosis of the spine (Pott disease). The prognostic significance of various clinical, radiological, and long-term follow-up findings in these patients was also evaluated.

Methods: Between January 2009 and January 2018 data were collected prospectively at The Neurosciences Hospital/ Baghdad/ Iraq in 44 patients with Pott disease in the thoracic and lumbar spine. These patients had no major neurological deficits or severe spinal deformities. The study population consisted of 21 male (48\%) and 23 female (52\%) patients, with a mean age of 42.1 years (range 10-70 years). The most common region of Pott disease was the thoracolumbar junction (18 cases; $41 \%$ ), followed by the thoracic (16 cases; 36\%) and lumbar (10 cases; 23\%) regions. With the exception of two cases, all had kyphotic angles less than $30^{\circ}$. At presentation, 20 patients had neurological signs of spinal cord compression during clinical examination. Clinical, radiological, and laboratory investigations findings were used in all cases for diagnosis. All patients were treated with anti-tuberculous drugs, and the disease in only two (4.5\%) was resistant to the regimen. The follow up period was 24 months.
Forty-two (95.4\%) of the 44 patients were successfully treated with conservative medical management and attained acceptable spinal deformity angles, and none of these patients had any residual instability, radiculopathy, or neurological compromise. Only $4.5 \%$ of the patients experienced residual spine deformity (as much as a $30^{\circ}$ kyphotic angle), which was clinically obvious but biomechanically stable.

Conclusions: Patients with Pott disease in the lumbar and thoracic regions, without neurological deficits or kyphosis, can be treated conservatively in the vast majority of cases. Indications for surgery need to be redefined given these new data.

Key words Tuberculosis, Pott disease, lumbar spine, thoracic spine, medical treatment

${ }^{1}$ Correspondence author: Assistant Professor of Neurosurgery/ M.B.Ch.B F.I.C.M.S (Neurosurgery) Consultant Neurosurgeon Al-kindy College of Medicine/ University of Baghdad

${ }^{2}$ Consultant Neurosurgeon M.B.Ch.B IFAANS

College of Medicine/ University of Baghdad

3 Neurosciences Hospital/ Baghdad-Iraq M.B.Ch.B

Received at 29/3/2018

Accepted at 1/8/2018

\section{INTRODUCTION}

I The incidence of Pott disease is now infrequent in developed countries but continues to be a public health problem in underdeveloped countries. ${ }^{(1,2)}$ Surgical treatment of patients with Pott disease is considered in cases of severe spinal instability or progressive neurological symptoms with evidence of cord compression or deformation. ${ }^{(2,3,4,5,5,6,7)}$ It is unclear, however, as to when medical management alone is the preferred treatment of Pott disease. The manipulation of neural tissue followed by correction of mild or severe spinal deformity with implants along with medical treatment have been shown to relieve pain, improve neurological impairment, and prevent deformity. ${ }^{(8,9,10,1)}$ Patients who have both neurological impairment and kyphotic deformity can be treated medically, and this treatment can 
be achieved with antituberculous drugs alone. Indications for surgery in these patients are few and specific. ${ }^{(4,8,12,13)}$

After the administration of antituberculous therapy, the acute infectious process resolves with the formation of fibrous scarring and ossification, which acts to restore stability. ${ }^{(14)}$ These treatment principles formed the basis of our prospective clinical study.

\section{METHODS}

In this study, we report on a series of 44 patients with Pott disease in the thoracic and lumbar regions who met the inclusion criteria for conservative medical treatment. The patients included in the study were seen at our hospital (The Neurosciences Hospital/ Baghdad/ Iraq) between January 2009 and January 2018. The roles of various clinical and radiological findings, including spinal deformities, and neurological complications, are also discussed.

In this prospective study we included patients with Pott disease with varying degrees of neurological deficit, who were treated with conservative medical treatment. The diagnosis of Pott disease was based on clinical, MR imaging, and laboratory investigations. The inclusion criteria were clinical, imaging and laboratory investigations findings that strongly suggested the presence of Pott disease. Exclusion criteria were advanced major motor deficit at the time of presentation, deteriorating neurological function that developed during antituberculous therapy, or spine deformity greater than an angle of $30^{\circ}$ at the affected level at the time of presentation. A sagittal plane displacement greater than $2.5 \mathrm{~mm}$ in the thoracic spine as demonstrated on lateral radiographs was considered potentially unstable. This criterion was based on experimental biomechanical studies in which stability criteria suggested for the cervical spine were determined. ${ }^{(15)}$ Likewise, a sagittal plane displacement greater than $4.5 \mathrm{~mm}$ in the lumbar spine, or $15 \%$ of the anteroposterior diameter of the vertebral body as demonstrated on a static lateral radiograph, was considered potentially unstable. ${ }^{(15)}$ Advanced major deficit was defined as paraparesis due to spinal cord compression in cases of thoracic spine involvement, and cauda equina syndrome due to compression of the cauda equina in cases of lumbar spine involvement. Patients were considered to have a severe spinal deformity if they had a score of at least 5 according to the criteria defined by White and Panjabi. ${ }^{(16)}$ We used direct spine radiographs and MR imaging to evaluate all the patients. Using direct radiography, spinal features such as osteopenia, disc space reduction, endplate erosion, and gross vertebral and costovertebral bone destruction and deformities were identified. A thorough medical history was recorded for each patient, and all patients underwent a detailed clinical evaluation. Neurological improvement was evaluated at each follow-up visit. Muscle power was tested and was given a score of 0 to 5 according to the Medical Research Council scale. ${ }^{(17)}$ Spinal cord function was evaluated using American Spinal Injury Association (ASIA) definitions. Muscle tone, reflexes, pinprick sensations, joint position, and vibration were tested and the presence of bone deformity and soft tissue tenderness or swelling was noted. Localized spinal deformity was measured as the angle between the upper and lower endplates of the collapsed vertebral levels following medical management, and at the last follow-up visit. On lateral $\mathrm{x}$-ray films, sagittal contours between the T2-12 and L1-5 vertebrae were measured using the Cobb method. These values were corrected by subtracting $5^{\circ}$ per level from the thoracic values and by adding $10^{\circ}$ per 
level to the lumbar angles. In determining the difference between local kyphotic angles before and after treatment, however, the correction of physiological kyphotic and lordotic angles was bypassed because the difference between the angles was that which was evaluated. Functional outcome after 24 months was defined as poor (bedridden or dependent on others for activities of daily living) or good (independent of others for activities of daily living).

The following laboratory investigations were performed in each patient:

complete blood count, erythrocyte sedimentation rate, serum chemistry, HIV serology, and polymerase chain reactions for tuberculosis. Radiographic examinations of the chest were also done for each patient. Medical treatment agents were administered using a standard protocol. Patients were treated with a standard four-drug treatment that included rifampicin $(15 \mathrm{mg} / \mathrm{kg}$; maximum 600 $\mathrm{mg} /$ day), isoniazid (5 $\mathrm{mg} / \mathrm{kg}$; maximum $300 \mathrm{mg} /$ day $)$, pyrazinamide $(25 \mathrm{mg} / \mathrm{kg}$; maximum $2 \mathrm{~g} /$ day), and ethambutol (15$25 \mathrm{mg} / \mathrm{kg}$; maximum $2 \mathrm{~g} /$ day), and were advised to rest for 15 months. Four drugs were administered for the first 4 months, except for pyrazinamide which was discontinued after the first 2 months of treatment; a three-drug regimen was administered for the next 13 months or longer until there was radiological and pathological evidence of regression. Adults received streptomycin in addition to the standard four-drug treatment, whereas children received a four-drug regimen that routinely avoided streptomycin. In adult patients, the usual dose of streptomycin varied from 750$1000 \mathrm{mg}$ depending on body weight and was administered intramuscularly every day for a period of 2 months. Our specialist in infectious diseases regularly supervised this treatment.
Lateral and anteroposterior radiographs were obtained immediately after medical treatment, and after 6 weeks, 6 months, 12 months, and 24 months of therapy. A successful treatment was defined as the absence of pain, maintenance of spinal curvature, and the absence of motion in the fused segment at 24 months as demonstrated on flexion/extension radiographs, all of which were dynamic and obtained while the patient was in erect position. Patients who were mobile were warned not to participate in any intense physical training, weight lifting, and all kinds of physical activity requiring extreme effort for a period of 10 months, but there were no restrictions on daily routine activities. Thoracolumbosacral or lumbosacral orthoses were used by all patients. We advocated an early period of recumbency at the beginning of drug treatment. The pain relief without use of analgesics was assessed by a self-scored Visual analog scale (VAS), in which a score of 0 represented no pain and 10 represented severe pain.

\section{RESULTS}

Our study sample consisted of 44 patients with Pott disease. Twenty-three of the patients were female (52\%), and 21 were male $(48 \%)$, with a mean age of 42.1 years (range 10-70 years). All patients reported a backache that had lasted a mean duration of 8.2 months (range 0.7-36 months). After beginning conservative medical management, 42 (95.4\%) of the 44 patients showed definite and persistent clinical response within 6 weeks, which was confirmed radiologically after 12 weeks of treatment (isoniazid, rifampicin, ethambutol, and pyrazinamide). Two patients who were treated with isoniazid, rifampicin, pyrazinamide, streptomycin, and morfazinamid instead of ethambutol, improved with this regimen, showing neurological and mechanical stability at 
the 6th week of treatment. The duration of treatment administration ranged from 15 to 18 months, until symptoms regressed and laboratory and radiological investigations showed signs of resolution of disease. A regression of spondylodiscitis was a sign of recovery as demonstrated on plain radiographs and MR images; spinal fusion occurred last.

The affected locations of the spine in our patients were the thoracic spine in 16 patients (36\%), the thoracolumbar junction in $18(41 \%)$, and the lumbar spine in 10 (23\%). The most commonly affected vertebra was L-1 in 10 cases (23\%), followed by T-12 in eight cases (18\%). As demonstrated on MR images, a single vertebra was involved in six patients (14\%), two vertebrae in $27(61 \%)$, and three vertebrae in $11(25 \%)$ in the thoracolumbar junction. Soft-tissue shadow was noted on MR images in 35 patients $(79.5 \%)$ and spinal cord compression in 30 patients $(68 \%)$. Four patients had pulmonary and two had lymph node tuberculosis. The Cobb angles before and after treatments were compared. Seven patients (16\%) had demonstrable pretreatment mechanical instability, using the clinical criteria of severe back pain, paraspinal muscle spasm, and painfully restricted movements of both the thoracic and lumbar spine Table (1). Complete relief of all symptoms was attained in 42 of these 44 patients post treatment. The average angulation was found to have increased from $11^{\circ}$ to $21^{\circ}$ at the follow- up examination. In two of the 44 patients the Cobb angle progressed beyond the acceptable limit of $30^{\circ}$ at the end of treatment. After the diagnosis and treatment of Pott disease, progression of the spinal deformity was detected in only the two patients who refused surgery; one of them had upper thoracic Pott disease (Fig. 1A and B), and the other had Pott disease in the region of the thoracolumbar junction (Fig. 1C and D).

Table (1). Patient's characteristics

\begin{tabular}{|l|l|}
\hline \multicolumn{1}{|c|}{ Variable } & \multicolumn{1}{|c|}{ No. \% } \\
\hline Gender & $21(48)$ \\
Male & $23(52)$ \\
\hline Female & \\
\hline Age (years) & $26(59)$ \\
$10-40$ & $11(25)$ \\
$41-60$ & $7(16)$ \\
$>60$ & $16(36)$ \\
\hline Affected spinal level & $18(41)$ \\
Thoracic & $10(23)$ \\
Thoracolumbar & \\
Lumbar & $7(16)$ \\
\hline Mechanical instability & $2(4.5)$ \\
Pretreatment & \\
Posttreatment & $6(14)$ \\
\hline Neurological signs & $2(4.5)$ \\
Pretreatment (ASIA grade D) & $38(86)$ \\
Posttreatment (ASIA grade & \\
D) & \\
Pretreatment (ASIA grade E) & $42(95.4)$ \\
Posttreatment (ASIA grade & \\
E) & \\
\hline Spinal deformity angle ( $\left.{ }^{\circ}\right)^{*}$ & $11 \pm 7$ \\
Pretreatment & $21 \pm 11$ \\
Posttreatment & 6.9 \\
\hline Mean VAS score & $1.7 * *$ \\
Pretreatment & 0 \\
Posttreatment (6 months) \\
Posttreatment (24 months) \\
\hline Means standavis \\
\hline
\end{tabular}

* Means \pm standard deviations.

** $p<0.001$, paired-sample t-test. 

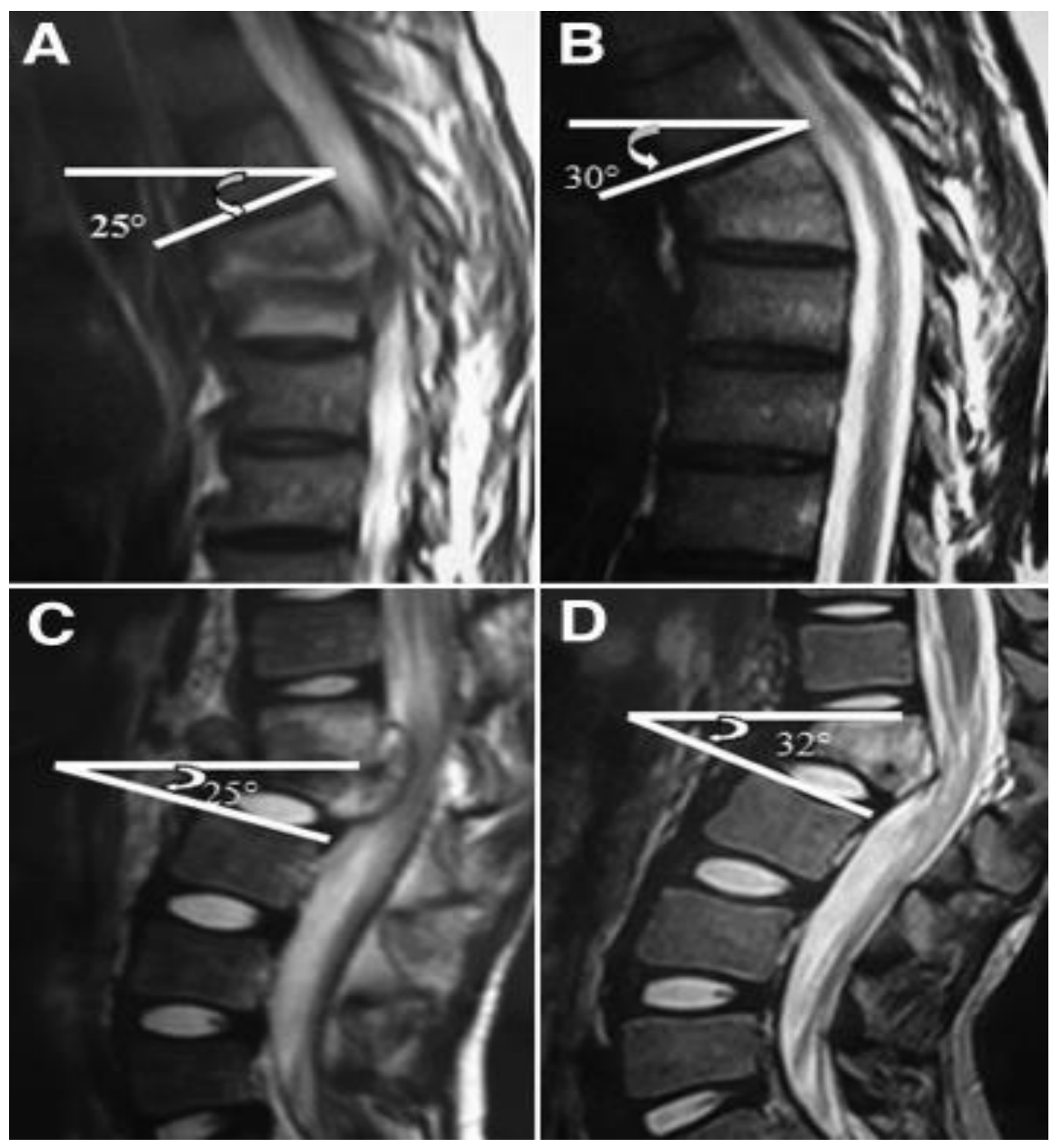

Figure (1). Sagittal MR images. A: Pretreatment image of the upper thoracic (T-1) region obtained in a 34-year-old woman with Pott disease. B: After the patient refused surgical treatment for her slight spinal deformity, the Cobb angle increased $5^{\circ}$ at the end of 15 months of treatment and remained at $30^{\circ} 2$ years after completion of treatment. C: Pretreatment image obtained in a 10 -yearold girl presenting with lumbar tuberculosis, back pain, an ASIA grade of $\mathrm{E}$, severe vertebral and disc destruction, and cord compression by tuberculous granulation tissue, and a spine deformity of $25^{\circ}$. D: Image showing good response to antituberculous drugs alone, after the patient's family had refused surgical

treatment. Evidence of bone fusion with mild deformity and an acceptable Cobb angle of $32^{\circ}$ are seen at the end of 14 months of treatment.

The clinical outcome was good in 42 patients at the end of 24 months. The presence of fusion on plain flexion/ extension radiographs supported this outcome. During the long-term follow up of all patients, only two cases (4.5\%) displayed progression in mechanical and neurological instability. We examined these patients and detected that their deformity angles were 30 and $32^{\circ}$, but they required assistance when walking. No instability was observed in 42 patients (Figs. 2,3, and 4). 

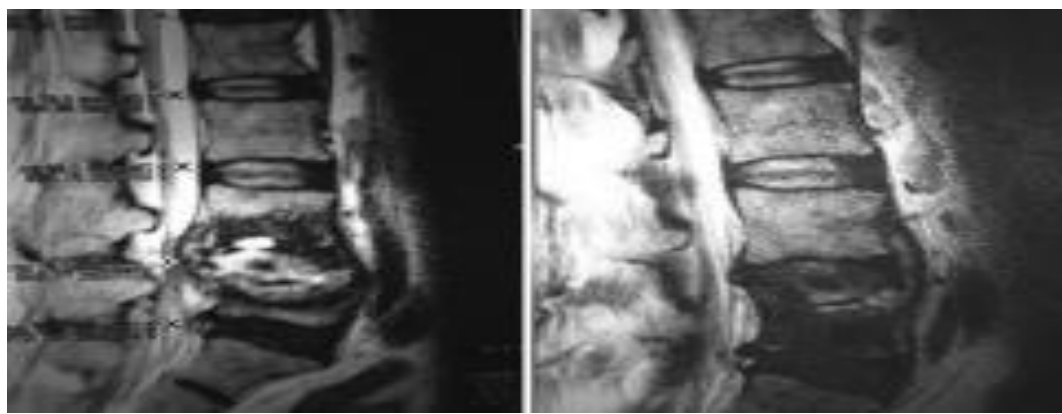

Figure (2). Pretreatment (left) and posttreatment (right) MR images obtained in a 66-year-old woman who presented with clinical instability, low-back pain, and bilateral sciatic pain. Left: Spondylodiscitis is evident at the L-5 level. Right: At the end of 16 months of medical management, she recovered completely, based on clinical and imaging findings, with no evidence of spinal deformity.
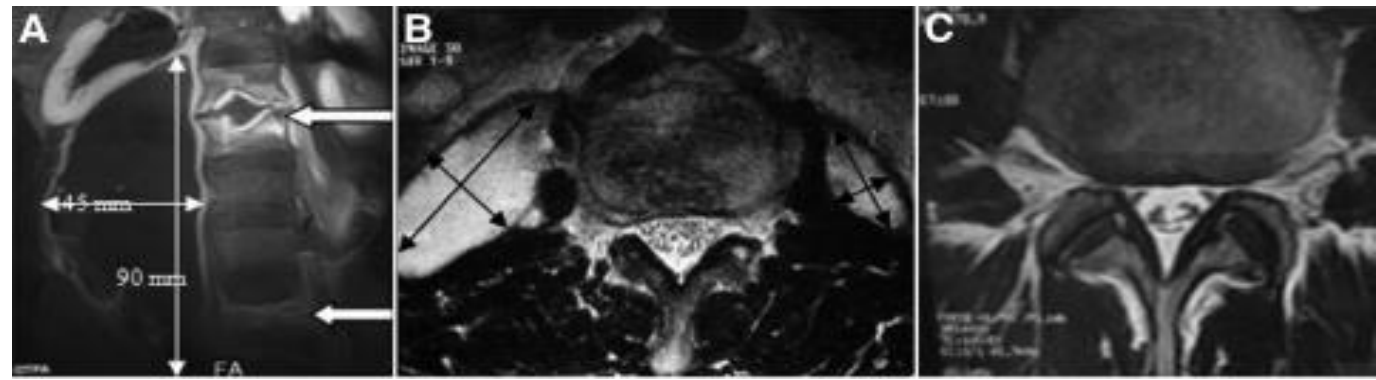

Figure (3). Pretreatment (A and B) and posttreatment (C) MR images obtained in a 22-yearold man presenting with giant intramuscular abscesses. A: Coronal image showing the affected two levels in the lumbar region (arrows). B: Axial image showing the locations of the abscesses (arrows). C: Axial image showing resolution of the abscesses at the end of 12 months of treatment.

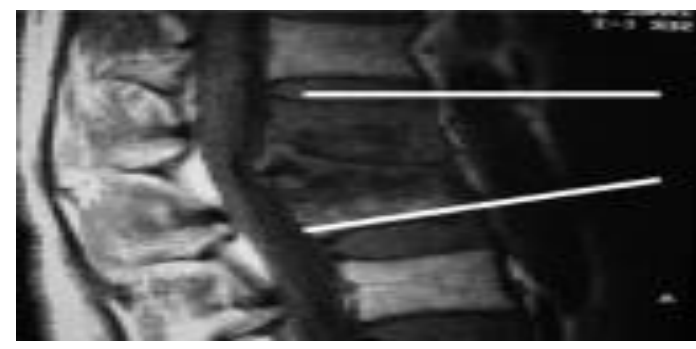

Figure (4).. Pretreatment (left) and posttreatment (right) MR images obtained in a 44-year-old man. Left: Image showing upper lumbar (L-1) Pott disease with a Cobb angle of $15^{\circ}$. Right: Image demonstrating excellent response to 19 months of antituberculous

treatment alone, evidence of bone fusion with mild deformity, and an acceptable Cobb angle of $17^{\circ}$.

The mean local spine deformity angle before medical treatment was $11 \pm 7^{\circ}$ (range $5-19^{\circ}$ ), and increased to $21 \pm 11^{\circ}$ (range $\left.10-32^{\circ}\right)$ after treatment $(p<0.001$, paired-sample t-test). Muscle strength was

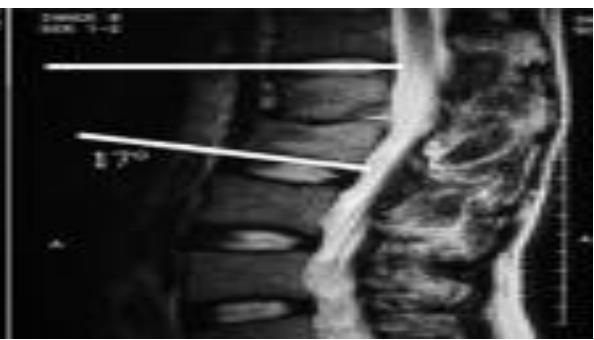

normal in 38 patients (86\%) with an ASIA grade of $\mathrm{E}$, but tendon reflexes were exaggerated in these patients, and loss of joint position sensations was noted. The other six patients (14\%) exhibited neurological deficits that could be interpreted as almost paraparesis; these patients were given an ASIA grade of D. These six patients had minor spasticity with hyperreflexia, suggesting pyramidal dysfunction. After medical treatment, four experienced complete recovery, but the conditions in the other two did not improve during follow up. At 6 months, 42patients (95.4\%) attained an excellent 
recovery, and two (4.5\%) had a poor recovery. At the 6-month follow up, the average VAS score had improved from a pretreatment score of 6.9 to a post treatment score of 1.7 ( $p<0.001$, pairedsample t-test). At the 24-month follow up, the average VAS score was 0 , characterized by full spinal fusion and no pain. All but two of the 44 patients (95.4\%) exhibited excellent spinal fusion and function, with no signs of residual instability or sensorimotor deficits.

\section{DISCUSSION}

Pott disease is the most common form of bone and joint tuberculosis in developing countries and constitutes 1-3\% of all cases of tuberculosis..$^{(1,9,18)}$ The role of surgery in Pott disease of the spine is still debatable. Much data have been published on the surgical treatment of Pott disease,,$^{(5,13,19,20,21,22)}$ but only a few articles on the medical management of Pott disease have been published. ${ }^{(4,8,12)}$ The incidence of tuberculosis is higher in immunocompromised patients, and there are reports in the literature that provide descriptions of surgical outcomes of Pott disease in patients infected with HIV. ${ }^{(23)}$ The management of Pott disease has thus become a more important problem now than it was in the recent past, ${ }^{(7,23,24,25,26)}$ although no patient in our series was found to be infected with HIV. Pott disease is the most dangerous form of skeletal tuberculosis because it can cause bone destruction, deformity, and paraplegia. ${ }^{(8,17,19,22,27)} \quad$ Tuberculous involvement varies widely; in this study, this involvement was greatest at the thoracolumbar junction, with decreasing frequencies at more rostral and caudal levels. The lumbosacral region may harbor tuberculosis better than other areas of the spine, but particular anatomical features of the lumbar and lumbosacral spine make tuberculous infection in this region amenable to conservative medical treatment. A capacious spinal canal, with floating nerve roots that function like peripheral nerves, can be relatively tolerant to compression because of abscess or granulation tissue, which may develop slowly. ${ }^{(12,19)}$

Surgery performed when Pott disease is active is safer and the response is faster and better than when it is performed after the disease has been cured. $^{(19)}$ Yet, neurological recovery following anterior surgery and fusion is not always satisfactory with regard to deformity correction. ${ }^{(15,20,28)}$

The graft failure rate due to fracture, migration, or subsidence is alarming (59\%). The graft may also sink into the cancellous vertebral bodies, causing exaggeration of the spinal deformity, especially in patients with involvement of two or more vertebrae and a graft length exceeding two or

more disc spaces. Lifeso et al. ${ }^{(20)}$ have reported an increase in the kyphotic deformity by an average of $0.6^{\circ}$ after anterior therapy. Authors of a recent study in the US recommended therapy and stabilization in Pott disease with neurological symptoms and signs. ${ }^{(9)}$ Most of the patients in that study improved, although two died. Because of these data, chemotherapy alone can be administered in patients with Pott disease. In our study, $95.4 \%$ of the patients showed full recovery at 6 months, and there were no deaths. Pott disease typically has an insidious onset and slow progression, although acute onset has been reported in the literature. ${ }^{(10)}$ Because of the low intensity of these symptoms patients usually seek attention weeks to months after onset of the original symptoms. The mean duration between the onset of symptoms and clinical presentation in our series was 11.2 months (range 4-24 months). Means of shorter duration have been reported in the literature..$^{(9,23,27,29)} \quad$ Constitutional 
symptoms such as low fever, malaise, and weight loss did not contribute to a diagnosis in any patient in our series. The reported incidence of neurological deficit in cases of Pott disease varies from 23 to $76 \% .^{(2,18,21,23,27,29,30,31,32)}$ The incidence of paraplegia is higher with spondylitis in the thoracic and cervical spine. ${ }^{(3,33,34,35,36)}$ Patients with neurological deficits may improve spontaneously without surgery and/or antituberculous drugs. ${ }^{(13)}$ The use of diagnostic procedures such as tissue cultures, antigen demonstrations, serology tests, and polymerase chain reactions are of the highest priority. ${ }^{(30)}$ In the present study, however, the polymerase chain reactions test was positive in only 19 cases. All paravertebral abscesses do not need to be drained because they may resolve with antituberculous drugs. Drainage of an abscess may be indicated if it causes symptoms that are simply due to its size and location. Modern imaging techniques such as MR imaging have changed the prognosis of patients with neurotuberculosis, ${ }^{(37)}$ because the pathological entity in the spinal cord can be discovered at an earlier stage. In recent years, MR imaging has emerged as the primary modality to accurately image the spine. ${ }^{(2,29,32,38,39,40,41,42,43,44,45,46,47)}$

Paraspinal abscess is another feature of tuberculosis, occurring in approximately $50 \%$ of these cases, whereas the frequency of paraspinal abscess complicating Pott disease is only $13 \% .^{(48)}$ Central body tuberculosis very closely resembles a neoplasm; an epidural tuberculosis granuloma without osseous involvement cannot be differentiated from an epidural neoplastic metastatic lesion. ${ }^{(37)}$

Deformity or kyphosis is a significant problem in Pott disease. Rajasekaran ${ }^{(49)}$ reported that the progress of deformity occurs in two distinct phases: Phase I includes the changes in the active phase, and Phase II includes changes after the disease is cured. The deformity progression is influenced by the severity of the angle before treatment, the level of the lesion, and the age of the patient. Adults have an increase of the kyphotic angle of less than $30^{\circ}$ during the active phase with no additional treatment. There is an average increase of $15^{\circ}$ deformity in all patients who are treated conservatively, and $3-5 \%$ of patients may end up with a deformity that is greater than $60^{\circ}$. Children, in contrast, have significant changes even in the healed phase of the disease. A solid spinal fusion is essential for permanent recovery from tuberculous spondylitis. Dobson ${ }^{(9)}$ reported that the fusion rate in patients treated by antituberculous drugs alone was $27 \%$, but there are no new data concerning spontaneous fusion. In our study, spontaneous bone fusion with medical management occurred in all patients during the follow-up period. At our hospital, any patients harboring a lesion suggestive of Pott disease are treated medically and undergo regular follow-up examination.

\section{CONCLUSION}

The management of Pott disease should be specific to each patient. Effective medical treatment for Pott disease is the gold standard and must be started at the early stages of the disease. Surgical intervention for Pott disease should only be considered in patients with the following conditions: 1) gross neurological and mechanical instability or spinal deformity; 2) poor response to medical treatment; 3) deterioration in neurological status during treatment; 4) any paradoxical enlargement of the lesion observed on follow-up MR images; or 5) intolerance to drugs.

If the angle of spinal deformity and neurological deficit are within acceptable limits, medical treatment alone of Pott 
disease will most often be sufficient in patients with a definitive diagnosis.

\section{References}

1. Grose GJ, Pais MJ, Kusske JA: Tuberculosis spondylitis. A report of 6 cases and a review of the literature. Medicine 62: 178-193, 1983

2. Hayes AJ, Choksey M, Barnes N, Sparrow OC: Spinal tuberculosis in developed countries: difficulties in diagnosis. J R Coll Surg Edinb 41:192-196, 1996

3. Garceau GJ, Brady TA: Pott's paraplegia. J Bone Joint Surg Am 32:87-95, 1950

4. Lancashire JD: Tuberculosis of the spine: an analysis of the results of conservative treatment and factors influencing prognosis. J Bone Joint Surg 33:517-531, 1951

5. Moula T, Fonles JV, Kassab MT, Sliman N: Pott's paraplegia: A clinical review of operative and conservative treatment in 63 adults and children. Int Orthop 5:23-29, 1981

6. Rezai AR, Lee M, Cooper PR, Errico TJ, Koslow M: Modern management of Pott's disease. Neurosurgery 36:87-98, 1995

7. Shridhar K: Tuberculosis of the spine, in Ramamurthi B, Tandon PN (eds): Textbook of Neurosurgery, ed 2. New Delhi: Churchill Livingstone, 1996, pp 496-513

8. Dobson J: Tuberculosis of the spine; an analysis of the results of conservative treatment and factors influencing prognosis. J Bone Joint Surg Br 33:517-521, 1951

9. Janssens JP, de Haller R: Pott's disease in a developed country. A review of 26 cases with special emphasis on abscesses and neurologic complications. Clin Orthop Relat Res 257:67-75, 1990

10. Mehta JS, Bhojraj SY: Tuberculosis of the thoracic spine. A classification based on the selection of surgical strategies. J Bone Joint Surg Br 83:859-863, 2001

11. Sharif HS, Aideyan OA, Clark DC, Madkour MM, Aabed MY, Mattsson TA, et al: Brucellar and tuberculous spondylitis: comparative imaging features. Radiology 171:419-425, 1989

12. Nene A, Bhojraj S: Results of nonsurgical treatment of thoracic spinal tuberculosis in adults. Spine J 5:79-84, 2005

13. Tuli SM: Results of treatment of Pott's disease by "middlepath" regime. J Bone Joint Surg 57:13-23, 1975
14. Konstam PG, Blesovsky A: The ambulant treatment of Pott's disease. Br J Surg 50:2638, 1962

15. Hausfeld JN: A Biomechanical Analysis of Clinical Stability in the Thoracic and the Lumbar Spine. Thesis. New Haven: Yale University School of Medicine, 1977

16. White AA, Panjabi MM: Clinical Biomechanics of the Spine, ed 2 . Philadelphia: Lippincott, 1990

17. Davidson PT, Horowitz I: Skeletal tuberculosis. A review with patient presentations and discussion. Am J Med 48:72-84, 1970

18. Nussbaum ES, Rockswold GL, Bergman TA, Erickson DL, Seljeskog EL: Spinal tuberculosis: a diagnostic and management challenge. J Neurosurg 83:243-247, 1995

19. Hsu LC, Cheng CL, Leong JC: Pott's paraplegia of late onset: the cause of compression and results after anterior therapy. J Bone Joint Surg Br 70:534-538, 1988

20. Lifeso RM, Weaver P, Harder EH: Tuberculous spondylitis in adults. J Bone Joint Surg Am 67:1405-1413, 1985

21. Moon MS, Moon YW, Moon JL, Kim SS, Sun DH: Conservative treatment of tuberculosis of the lumbosacral spine. Clin Orthop Relat Res 398:40-49, 2002

22. Turgut M: Spinal tuberculosis (Pott's disease): its clinical presentation, surgical management, and outcome. Neurosurg Rev 24:8-13, 2001

23. Leibert E, Schluger NW, Bonk S, Rom WN: Pott's disease in patients with human immunodeficiency virus infection: clinical presentation, therapy and outcome. Tuber Lung Dis 77: 329-334, 1996

24. Kalita J, Misra UK, Mandal SK: Prognostic predictors of acute transverse myelitis. Acta Neurol Scand 98:60-63, 1998

25. Misra UK, Kalita J, Kumar S, Mathur A: Radiological and neurophysiological changes in Japanese encephalitis. J Neurol Neurosurg Psychiatry 57:1484-1488, 1994

26. Misra UK, Sharma VP, Singh VP: Clinical aspects of neurolathyrism in Unnao, India. Paraplegia 31:249-254, 1993

27. Cotten A, Flipo RM, Drouot MH, et al: [Spinal tuberculosis. Study of clinical and 
radiological aspects from a series of 82 cases.] J Radiol 77: 419-426, 1996 (Fr)

28. Loembe PM, Mwanyombet-Ompounga L, Assengone-Zeh Y, Kengue-Lechiombeka PR: [Early anterolateral surgery for tuberculosis of the lower cervical spine with neurological complications in adult. Our experience in Gabon.] Neurochirurgie 46:541-548, 2000 (Fr)

29. Colmenero JD, Jimenez-Mejias ME, Sanchez-Lora FJ, et al: Pyogenic, TB, and brucellar vertebral osteomyelitis: a descriptive and comparative study of 219 cases. Ann Rheum Dis 56:709-715, 1997

30. Azzam NI, Tammawy M: Tuberculosis spondylitis in adults. Diagnosis and treatment. Br J Neurosurg 2:85-91, 1988

31. Medical Research Council Working Party on TB of the Spine: A comparison of 6 or 9month course regime of chemotherapy in patients undergoing radical surgery for TB of the spine. Ind J Tuberc (36):1-29, 1989

32. Perronne C, Saba J, Behloul Z, SalmonCeron D, Leport C, Vilde JL, et al: Pyogenic and tuberculous spondylodiskitis (vertebral osteomyelitis) in 80 adult patients. Clin Infect Dis 19: 746-750, 1994

33. Misra UK, Kalita J: Motor evoked potential is useful for monitoring the effect of collar therapy in cervical spondylotic myelopathy. J Neurol Sci 154:222-228, 1998

34. Misra K, Kalita J: Somatosensory and motor evoked potentials in patients with Pott's paraplegia. Spinal Cord 34:272-276, 1996

35. Misra UK, Kalita J, Das A: Vitamin B12 deficiency neurological syndromes: a clinical, MRI and electrodiagnostic study. Electromyogr Clin Neurophysiol 43:57-64, 2003

36. Moon MS, Ha KY, Sun DH, Moon JL, Chung JH: Pott's paraplegia-67 cases. Clin Orthop Relat Res 323: 122-128, 1996

37. Smith AS, Weinstein MA, Mizushima A, et al: MR imaging characteristics of TB spondylitis vs vertebral osteomyelitis. AJR Am J Roentgenol 153:399-405, 1989

38. Ahmadi J, Bajaj A, Segall HD, Zee CS: Pott's disease: Atypical observations at MR imaging. Radiology 189: 489-493, 1993

39. Al-Mulhim FA, Ibrahim EM, el-Hassan AY, Moharram HM: Magnetic resonance imaging of Pott's disease. Spine 20: 2287-2292, 1995
40. Arizono T, Oga M, Shiota E, Sugioka Y: Differentiation of vertebral osteomyelitis and Pott's disease by magnetic resonance imaging. Int Orthop 19:319-321, 1995

41. Desai SS: Early diagnosis of Pott's disease by MRI. J Bone Joint Surg Br 76:863-867, 1994

42. Kim NH, Lee HM, Suh JS: Magnetic resonance imaging for the diagnosis of Pott's disease. Spine 19:2451-2455, 1994

43. Lanzieri C: Magnetic resonance imaging of infections of the spine, in Haaga JR, Lanzieri CF, Gilkeson RC (eds): CT and MR Imaging of the Whole Body, ed 4. St. Louis: EUA, 2003, pp 809-810

44. Lindahl S, Nyman RS, Brismar J, Hugosson C, Lundstedt C: Imaging of tuberculosis. IV. Spinal manifestations in 63 patients. Acta Radiol 37:506-508, 1996

45. Liu GC, Chou MS, Tsai TC, Lin SY, Shen YS: MR evaluation of tuberculous spondylitis. Acta Radiol 34:554-558, 1993

46. Maiuri F, Iaconetta G, Gallicchio B, Manto A, Briganti F: Spondylodiscitis. Clinical and magnetic resonance diagnosis. Spine 22:1741-1746, 1997

47. Wirtz DC, Genius I, Wildberger JE, Neithard FU: Diagnostic and therapeutic management of lumbar and thoracic spondylodiscitis - an evaluation of 59 cases. Arch Orthop Trauma Surg 120:245-251, 2000

48. Sole-Lianes J, Rotes-Querol J, Dalmau-Ciria M: Radiologic aspects of spinal brucellosis. Acta Radiol Diagn (Stockh) 5: 1132-1139, 1966

49. Rajasekaran S: The problem of deformity in spinal tuberculosis. Clin Orthop Relat Res 398:85-92, 2002 